\title{
Jogos digitais: uma abordagem educacional à luz da Epistemologia Genética
}

\author{
Maria Letícia Felicori Tonelli e Teixeira Leite* \\ Patricia Bebling Schäfer ** \\ Daniela Szabluk ${ }^{* * *}$ \\ Helvia Pereira Pinto Bastos ${ }^{* * * *}$ \\ Suzana da Hora Macedo ${ }^{* * * *}$ \\ Mauricio José Viana Amorim ${ }^{* * * * *}$ \\ Rodney Cezar de Albuquerque ${ }^{* * * * * * *}$
}

Eliane Vigneron Barreto Agniar ${ }^{* * * * * * *}$

Léa da Cruz Fagundes ${ }^{* * * * * * * *}$

* Doutoranda em Informática na Educação (UFRGS), mestre em Educação (UFF, 2004), possui bacharelado e licenciatura em Ciências Biológicas (UFMG, 1977). Professora do IFF- campus Macaé desde 1993, atua com turmas de Ensino Médio e PROEJA. E-mail: maria.leticiatonelli@gmail.com

* Doutoranda em Informática na Educação, mestre em Psicologia Social e Institucional e bacharel em Comunicação Social com habilitação em Publicidade e Propaganda pela UFRGS. Pesquisadora do Laboratório de Estudos Cognitivos (LEC/UFRGS). E-mail: patricia@lec.ufrgs.br

*** Mestranda do programa de Pós-Graduação em Design da UFRGS, bacharel em Design pelo Centro Universitário Ritter dos Reis (2008) e tecnóloga em Hotelaria pela Universidade de Caxias do Sul (2001). Atua como designer. E-mail: danisza@gmail.com

**** Doutoranda em Informática na Educação (UFRGS), mestre em Cognição e Linguagem (UENF, RJ, 2002), especialista em Linguística Geral e Aplicada (1994), possui licenciatura em Letras (FAFIC, RJ, 1974). Professora de Inglês Instrumental e de Metodologia da Pesquisa nos Cursos Superiores de Tecnologia e de Especialização do IFF- campus Campos-Centro, desde 1992. E-mail: helviabastos@yahoo.com.br 
Resumo: $\mathrm{O}$ artigo discute a propriedade do uso de jogos digitais no processo de aprendizagem e no diagnóstico do nível de conceituação a partir da consideração de regras sob uma perspectiva piagetiana. Com base na aplicação do conceito de ludicidade em sala de aula e na importância da informática na formação da práxis e implementação de uma nova cultura, busca-se apreender as maneiras pelas quais alunos matriculados no primeiro ano do Ensino Fundamental de nove anos descobrem e apropriam-se das regras constantes em jogos digitais. Para o experimento, utiliza-se o Método Clínico Piagetiano. O jogo escolhido é o Implode, software constante do XO, laptop concebido pela

***** Engenheira eletricista, doutoranda em Informática na Educação (UFRGS), Mestre em Tecnologia pelo CEFET-RJ (1998). Especialista em Análise de Sistemas, Sistemas Elétricos e Tecnologia Educacional e Didática. Professora do IFF-campus Campos Centro, desde 1987. Gerente de Ensino na implantação do IFF-campus Itaperuna (2009). E-mail: shmacedo@iff.edu.br

Doutorando em Informática na Educação (UFRGS), mestre em Sistemas de Informação (IME, 1998), graduado em Sistemas de informação pela Universidade Católica de Petrópolis (1990). É professor e coordenador do IFF- campus Campos Centro. Possui experiência na área de Ciência da Computação, com ênfase em Inteligência Artificial, Banco de Dados e Ambientes Virtuais de Aprendizagem. E-mail: amorim@iff.edu.br

****** Graduado em Tecnologia em Processamento de Dados pela UVA (1997), especialista em Marketing pela UCAM (1998), mestre em Ensino de Ciências da Saúde e do Ambiente pela UNIPLI (2005) e doutorando em Informática na Educação do PPGIE/UFRGS. Professor de informática e diretor do Campus Avançado Engenheiro Paulo de Frontin do IFRJ. E-mail: rodney.albuquerque@ifrj.edu.br

* Doutoranda em Informática na Educação (UFRGS), mestre em Educação Matemática (Universidade Santa Úrsula, 1999) e graduada em Ciências com habilitação em Matemática (Faculdade de Filosofia de Campos, 1985). Professora de Matemática do IFF-campus Campos Centro, desde 1996. E-mail: elianevig@yahoo.com.br * Professora titular aposentada da UFRGS, docente nos programas de PósGraduação em Psicologia Social e Institucional e em Informática na Educação, Coordenadora de pesquisa do Laboratório de Estudos Cognitivos (LEC/UFRGS). Possui doutorado em Psicologia Escolar e do Desenvolvimento Humano (USP), mestrado em Educação (UFRGS) e graduação em Psicologia e Pedagogia (UFRGS). E-mail: leafagun@ufrgs.br 
organização OLPC e integrante do pré-piloto do programa UCA Brasil SEED/MEC.

Palavras-chave: Computadores; Educação; Jogos Digitais.

Abstract: This paper discusses the applicability of digital games in learning processes and in assessing the level of conceptualization from Piaget's study of rules. Considering the debate over having "playful" educational activities in the classroom, and the relevance of computer science in developing as well as implementing new praxis and culture, the study aims at understanding how First Grade students discover and acquire constant rules in digital games. The experiment was carried with Piaget's clinical method. The game is Implode, embedded in the XO laptop conceived by OLPC organization, and tested in the first stage of the investigation developed by UCA Brazil SEED/MEC project.

Keywords: Computers; Education; Games.

\section{Introdução}

A décima edição do Systema Naturae de Carolus Linnaeus, publicada em 1758, é um marco na história natural, uma vez que estabelece as regras para a taxonomia e nomenclatura de animais e vegetais (MAYR, 1998). Embora estejamos no século $\mathrm{XXI}$, as bases ali colocadas são válidas ainda hoje. A espécie era - e continua sendo - a unidade de pesquisa/conhecimento dos organismos. É binominal, com os termos referentes escritos em latim - o idioma científico da época. Assim, surgiu a referência ao Homo sapiens para designar todos os constituintes de nossa espécie. Foi ali definida enfatizando sua característica de aprendizagem, de socialização dessa aprendizagem, de construção e reconstrução do meio.

Com o passar do tempo, a sociologia, a antropologia, a filosofia, entre outros campos de conhecimento, apropriaram-se e transformaram a denominação biológica da espécie. Dessa 
forma, falamos em Homo faber para nos referirmos à condição humana das revoluções industriais, ou em Homo ludens para enfatizar a característica humana relacionada com as brincadeiras, os jogos, as estratégias e os rituais que, segundo Huizinga $(2008)^{1}$, apontam variantes da mesma qualidade: a ludicidade. Mais recentemente, Veen e Vrakking (2009) cunharam Homo zappiens, buscando referir-se à geração nascida na 'era informacional'. Zapear é atributo dessas pessoas e diz respeito às maneiras e velocidades diversas com que se relacionam com eletro-eletrônicos. Dito de outra maneira, remete ao passeio rápido pelos canais televisivos, proporcionado pelo uso contínuo do controle remoto, à agilidade de cliques com o mouse no uso do computador, à rápida apropriação dos novos instrumentos ligados à telefonia - celulares, GPS, smartphones. Em 2001, Veen já considerava que o Homo zappiens aprendera a transitar na internet de forma eficiente, a se comunicar e a produzir usando as redes sociais. Essas experiências permitem à criança desenvolver sua aprendizagem de forma exploratória e dar significado às informações encontradas. Para esse autor, o Homo zappiens é auto-direcionado, um bom solucionador de problemas e um comunicador experiente.

Os games têm a propriedade de instigar o usuário a explorar o seu funcionamento e a descobrir as ferramentas e estratégias mais adequadas para alcançar seus objetivos, favorecendo, dessa forma, o desenvolvimento de várias habilidades metacognitivas. Entendemos que tanto o aspecto da ludicidade como a possibilidade de zapeamento devem ser utilizados na construção do conhecimento. Embora o aluno de hoje seja o de sempre - aquele que deve aprender -, 'aprender' pode tomar contornos mais distintos. Partimos da concepção, segundo a Epistemologia Genética (PIAGET, 1976, 1983, 1990), de que todos construímos nosso conhecimento. Assim, aprender não é ato passivo, de mão única, no sentido do professor para o aluno. Antes, é um processo inte-

\footnotetext{
1 A interação civilização-jogos aparece nas obras de Johan Huizinga (1872-1954) desde 1903, culminando com a edição original de Homo Ludens - Vom Ursprung der Kultur im Spiel, em 1938. Utiliza-se, nesse artigo, a tradução de 2008, editada no Brasil.
} 
rativo, que deve propiciar ao aluno pleno envolvimento, graças a sua característica não-linear. Segundo Lévy (1996, p. 40), “[...] quanto mais ativamente uma pessoa participar da aquisição de um conhecimento, mais ela irá integrar e reter aquilo que aprender". $\mathrm{E}$, ao 'tomar o aprendizado com as mãos', nossos alunos nos mostram que esse ato pode e deve ser prazeroso, principalmente quando em consonância com peculiaridades a que referimos: divertimento e zapeamento.

Nesse artigo, discutem-se os jogos como integrantes das diversas culturas, de variados rituais, e ainda seu papel constitutivo no desenvolvimento cognitivo de crianças. Igualmente, busca-se abordar os jogos eletrônicos - os games - como ferramenta passível de uso no processo de aprendizagem, mormente devido às condições propiciadas por ambiente informatizado: credibilidade de ações e velocidade de cálculos, traduzindo-se na imersão do aluno no ambiente do jogo. Foram realizados experimentos com alunos em idades que apontam estágios de desenvolvimento cognitivo limítrofes - pré-operatório/operatório concreto -, utilizando jogos de regras, não narrativos, já caracteristicamente indicados para o estágio operatório formal, quando as crianças se apropriam das regras para jogar com o outro. No caso específico, o 'outro' é o laptop, ambiente que suporta o jogo.

\section{Os jogos}

Huizinga (2008) aponta que jogar faz parte das diversas culturas humanas, apresentando gradações e significados diferentes ao longo da vida da pessoa e da sociedade na qual se encontra imersa. $\mathrm{O}$ aspecto lúdico encontrado em jogos e brincadeiras, dessa forma, é constitutivo da personalidade humana, levando o autor a denominar nossa espécie Homo ludens. Ainda na visão do autor, para ser lúdica, a atividade deverá apresentar determinadas características, discutidas a seguir. 
Inicialmente, o jogo é livre, não obrigatório, voluntário. Não se pode obrigar o indivíduo a participar da atividade, sob pena de descaracterizá-la. De certa forma, escapa à vida real; portanto, não é séria. Admitida em momentos da vida infantil, a atividade precisa ser revestida de rituais para ser aceita na vida adulta. Outro aspecto concernente ao jogo é sua exterioridade: ele é desinteressado, não relacionado à satisfação de necessidades materiais e biológicas. Está fora da vida comum, cotidiana, aplicada à sobrevivência individual ou do grupo. E é finito. Acaba. No entanto, fixa-se ao pensamento e às lembranças, tornando-se repetitível, embora admita variações. Ele é dinâmico. O jogo tem regras e não se pode desrespeitá-las. Ao desrespeitar as regras, o jogador, parte de uma confraria, é desligado de sua prática e desterritorializado de sua comunidade. Esse jogador poderá formar novo grupo, sujeito a regras diferentes, mas que novamente deverão ser seguidas. Essas características ligam-se à reinvenção do jogo e à conservação da sua estrutura interna. Da conjunção dos elementos de ritmo e harmonia, os jogos apresentam o elemento tensão e são ditos cativantes, fascinantes. A tensão é um elemento importante porque se vincula à incerteza, ao acaso, à ideia de que 'ganhar o jogo' está relacionado com o empenho, o esforço. Essa tensão é parte da mística que se desenvolve e envolve aquele que joga. Assim, o jogo tem um caráter especial e excepcional no qual as leis e os costumes da vida cotidiana perdem a validade. É o próprio Huizinga que resume as características do jogo, anteriormente apontadas:

[...] atividade livre, conscientemente tomada como "não séria" e exterior à vida habitual, mas ao mesmo tempo capaz de absorver o jogador de maneira intensa e total. É uma atividade desligada de todo e qualquer interesse material, com a qual não se pode obter qualquer lucro, praticada dentro de limites espaciais e temporais próprios, segundo uma certa ordem e certas regras. Promove a formação de grupos sociais com tendência a rodearem-se de segredo e a sublinharem sua diferença em relação ao resto do mundo por meio de disfarces ou outros meios semelhantes (HUIZINGA, 2008, p. 16). 
Entretanto, para ser aceito como atividade pedagógica, o jogo $^{2}$ ou atividade lúdica deverá prescindir de algumas de suas características e redirecionar outras, tornando-se mais flexível. Em princípio, ele deixa de ser livre, embora isso possa ser minimizado se a ferramenta não for de uso obrigatório para toda uma turma. E há também a questão do lucro. Se caracterizarmos lucro como algo passível de rentabilidade imaterial e considerarmos que o aluno se apropria de jogos na construção do conhecimento, não poderemos considerar a característica da não-lucratividade nos jogos pedagogicamente utilizados. Não obstante, a tensão, a proposição de regras, a exterioridade à vida cotidiana conservam o caráter lúdico da ação proposta.

\section{Jogos Eletrônicos: os Games}

Atualmente, podem ser considerados games ou videogames todos os jogos em ambientes digitais. Esses jogos já foram categorizados separadamente como (i) para computadores, que usam o monitor do computador a partir de um hardware; (ii) para consoles, que ocorrem no monitor de televisão a partir de console próprio; e (iii) para arcades, também denominados fliperamas. Outras classificaçôes usuais para videogames levam em consideração o local onde o jogo se desenvolve - por exemplo, jogos desenvolvidos para arcades em shopping centers apresentam características de jogabilidade diferentes daquelas de jogos realizados em consoles domésticos. Podem ainda apresentar uma narrativa, embora esta se encontre mais na área do vivido, do experimentado (BENJAMIN, 1992), ou seja, do passado, enquanto um jogo se caracteriza mais pela ação que se desenvolve no presente. Entretanto, a cada dia, essa narrativa vem se integrando ao jogo, principalmente se pensarmos nos $\mathrm{MMORPG}^{3}$.

2 No contexto desse artigo, consideramos como educativo o jogo utilizado como ferramenta pedagógica.

3 O MMORPG - Massive Multiplayer Online Role-Playing Game - consiste em jogos de computador que permitem a interação simultânea de um grande número de jogadores em um mesmo ambiente virtual dinâmico. 
Neles, pode-se identificar o ambiente no qual se desenrolam histórias, preponderantes em relação a um jogo na acepção da palavra. A relação entre os avatares ${ }^{4}$ e suas interações sociais é que vai determinando a ação.

É preciso ainda que se atente para o fato de que alguns jogos são basicamente estruturas, carecendo de narrativa para unir suas partes constituintes, mas baseando-se na percepção daquilo que se passa na tela, como é o caso, por exemplo, de Pac-Man e Tetris. Inicialmente muito comuns entre os games, com o passar do tempo e com as inovaçôes tecnológicas possíveis, esses jogos foram substituídos por outros mais complexos. Afinal, os computadores são insuperáveis em dois aspectos: criação de paisagens credíveis e velocidade de cálculos para sua implementação.

Ao refletir sobre jogos e meios digitais, Murray (2003) afirma que esses últimos apresentam as propriedades de serem (i) procedimentais, uma vez que o computador tem capacidade de executar regras e procedimentos; (ii) participativos, uma vez que o computador, não apenas reflete comportamentos gerados por meio de regras, mas também permite a indução de comportamento, participação e interação; (iii) espaciais, pela capacidade de representar espaços navegáveis através da descrição verbal e do uso de imagens; (iv) e enciclopédicos, devido à grande quantidade de informaçốes disponíveis para armazenamento, manipulação e recriação de arquivos. Vistos sob a ótica do jogador, três aspectos podem ser apontados e considerados na condição de prazer: (i) a imersão, que permite a sensação de envolvimento numa realidade estranha, ensejando a fantasia livre em ambiente simulado; (ii) a agência advinda do fato de que quanto mais imerso, mais se deseja agir na consecução de resultados tangiveis; e (iii) a transformação, permitindo a tomada de decisões que não terão consequências diretas na realidade exterior, possibilitando o refazer e o reinício de experimentações, conforme o desejo pessoal.

4 Avatares são representações de internautas, quer na forma bidimensional (2D, nos fóruns, por exemplo), quer na tridimensional (3D, como acontece em alguns jogos). A palavra avatar tem sua origem na tradição hindu, em que designa a encarnação de uma divindade na Terra. 
O jogo possibilita que o jogador tenha acesso aos objetos que estimulam suas fantasias e experiências subjetivas. Este meio tecnológico torna-se mais atrativo para a infância ao virtualizar seus sonhos em forma de cores, sons e movimentos. Utilizado como ferramenta pedagógica, o jogo propicia o processo de busca e construção do conhecimento de forma não-linear, por meio de associações constituintes de múltiplas redes. Assim, a atividade de jogar se aproxima do trabalho cognitivo natural, favorecendo a aprendizagem.

\section{Os jogos na educação}

Segundo Prensky (2007), a aprendizagem baseada em jogos (digital game-based learning) surgiu com o boom tecnológico no final do século XX. Isso significa que a atual geração de alunos cresceu no mundo digital, fato que os levou a "[...] pensar e processar informações de forma totalmente diferente de seus antepassados" ${ }^{\prime 5}$. Como imigrantes digitais, os professores precisam se adaptar às novas formas de aprender e se comunicar de seus alunos - nativos digitais. Prensky considera os jogos uma importante ferramenta que atende às necessidades e aos estilos desses alunos. $\mathrm{O}$ autor reafirma sua crença de que a aprendizagem vai se tornar "[...] verdadeiramente centrada no aluno e divertida" - para alunos, professores, pais e gestores. E também assinala que o "muro" que tradicionalmente separava a aprendizagem da diversão irá ruir devido à impossibilidade dos educadores de resistir a essa demanda. Ainda focando o conceito de 'migrante digital', Prensky $(2009 ; 2010)$ alerta para uma possível confusão entre o que conceituou como "verbo" e "substantivo". Dessa forma, considera que verbo (verb) se refere a habilidades que o aluno precisa desenvolver para se tornar um cidadão produtivo. Como exemplo, cita "aprender a aprender", "cooperar", "pensar

5 No original: "think and process information fundamentally differently than their predecessors". 
criticamente", "expor logicamente", "ser criativo, persuasivo", ou seja, habilidades de longa duração, cujo significado permanece o mesmo ao longo do tempo. Por sua vez, substantivos (nouns) mudam rapidamente e se referem às tecnologias usadas na consecução dos verbos; são as ferramentas, daí a rapidez na sua substituição. $\mathrm{O}$ autor coloca que, por vezes, o professor foca a tecnologia, enquanto o aluno se entusiasma com a ação. E enquanto o professor se perde em PowerPoint, Word, Excel, o aluno procura comunicar-se, compartilhar, apresentar. Ocorre, então, um descompasso entre o que se pretende ensinar e aquilo que o aluno efetivamente aprende, uma vez que a transitoriedade dos softwares e hardwares é rapidamente assimilada e acompanhada pelos alunos, não pelos professores.

A visão de educação com ludicidade ${ }^{6}$ é corroborada por Papert (1998) quando atesta que, ao se envolver efetivamente num game, a criança demonstra um alto grau de "sofisticação" na sua forma de pensar e expressar como aprendeu e apreendeu o jogo. Para Papert (1998), ao descobrir as regras e estratégias de um jogo, a criança está, na verdade, aprendendo a aprender, uma vez que cada novo jogo se constitui em um projeto de aprendizagem bem demarcado, "com início, meio e fim", e cujos resultados dependem exclusivamente do indivíduo, diferentemente da aprendizagem escolar, em que um adulto decide o quê, como e quando aprender. Papert (1998) considera inevitável a tendência de que, em breve, os alunos sejam, eles mesmos, os desenvolvedores de seus próprios jogos.

Van Eck (2006) relaciona os ganhos cognitivos dos jogos à visão piagetiana de 'processo de desequilíbrio' resultante da constante alternância entre assimilação e acomodação. Van Eck (2006) explica que a desequilibração e a resolução são inerentes aos jogos. Nesse sentido, interagir com um jogo implica a formulação, testagem e revisão de uma hipótese. Segundo Van Eck (2006), esse processo ocorre de forma rápida e frequente durante o jogo em virtude do feedback imediato fornecido ao jogador.

6 Do inglês "edutainment" (education + entertainment). 
Nessa perspectiva, o jogo constitui uma ferramenta pedagógica quando permite um "ciclo contínuo de desequilíbrio e resolução (por assimilação e acomodação)".

Ainda sob o ponto de vista da cognição e analisando os processos dos jogos sob uma ótica construtivista, Macedo et al. (2000, p.18) apontam quatro etapas que resultam em uma real mudança de nível do jogador: (a) exploração dos materiais e aprendizagem das regras, (b) prática do jogo e construção de estratégias, (c) resolução de situações-problema e (d) análise das implicações do jogar. Na primeira etapa, há uma série de atividades exploratórias através das quais o jogador toma conhecimento das regras e do contexto do jogo. Essa compreensão das regras depende do desenvolvimento cognitivo da criança. A segunda etapa corresponde especificamente ao ato de jogar. Ao jogar, a criança exercita suas habilidades mentais criando estratégias para vencer - por isso, o autor enfatiza que, nesta etapa, deve-se incentivar a criança a jogar bem, valorizando disciplina, concentração, persistência e flexibilidade. Na etapa de resolução de situaçốesproblema, a criança é desafiada a buscar respostas e alternativas para as situações impostas, o que evidencia um importante recurso para a prática escolar. Finalmente, a quarta etapa compreende uma análise da experiência de jogar e suas implicações, como conquistas, superações, possíveis erros e diferentes soluções para um desafio, como forma de ampliar o olhar sobre o objeto.

Macedo et al. (2000) assinalam ainda que o valor educacional dos jogos em grupo pode ser bastante ampliado se pensarmos numa perspectiva piagetiana. Piaget (1990) via nos jogos não apenas uma forma de entretenimento para as crianças, mas um meio que enriquece o desenvolvimento intelectual. Por meio da participação em atividades com jogos, as crianças ganham autoconfiança e são incentivadas a serem produtoras de suas ações. Ao utilizar meios lúdicos, a escola dispõe da possibilidade de mobilizar diferentes sistemas de significação, instigar o pensamento e enriquecer ambientes com vistas ao desenvolvimento integral da criança. 


\section{Uma abordagem piagetiana do jogo}

Piaget $(1990)^{7}$, ao estudar a gênese e o desenvolvimento do jogo pela criança, inicialmente considera a caracterização daquilo que se conhece por 'jogo'. Para Piaget (1990), os critérios em geral utilizados para separar atividades lúdicas de não-lúdicas não são tão concretos, refletindo, ao contrário, uma questão de gradação ou intensidade. Exemplificando: o caráter 'desinteressado' anteriormente apontado constitui-se numa imprecisão, uma vez que o resultado da atividade interessa, e muito, ao jogador. Em relação à espontaneidade, Piaget alerta que muitas atividades hoje consideradas 'sérias' originaram-se de inquirições espontâneas, que mais tarde levaram ao desenvolvimento de uma miríade de ciências. Conclui, dessa forma, que o jogo se caracteriza "essencialmente [como] assimilação, ou assimilação predominando sobre a acomodação" (ibid, p. 115). Tal dado resulta da necessidade em que se encontra a criança de se expressar, mesmo quando distante de algumas condições de descentração:

Do ponto de vista do significado, o jogo permite ao sujeito reviver suas experiências vividas e tende mais à satisfação do eu que à sua submissão ao real. Do ponto de vista do significante, o simbolismo oferece à criança a linguagem pessoal viva e dinâmica, indispensável para exprimir sua subjetividade intraduzível somente na linguagem coletiva. (ibid, p. 214)

O Piaget (1990) identifica três grandes tipos de estruturas que caracterizam os jogos infantis: o exercício, o símbolo e a regra. Ao primeiro tipo correspondem as condutas exercitadas 'em vazio', pelo mero prazer de seu funcionamento, ainda sem evocação mental ou construção de imagens que remetam a outros elementos. Elas não supõem a intervenção do pensamento ou de estruturas representativas exclusivamente lúdicas. Os jogos de 'Exercício' que se incorporam aos esquemas de ação sensóriomotores não se esgotam nos primeiros meses de vida da criança.

7 Essa obra tem sua primeira edição em 1945. La formation du symbole chez l'enfant: imitation, jeu et rêve, image et representation Neuchâtel; Paris: Delachaux et Niestlé. (2e éd. 1959, 3e éd. 1964, 4e éd. 1968, 5e éd. 1970, 6e éd. 1976, 7e éd. 1976. 8e éd. 1994.)". 
Reaparecem durante toda a infância e mesmo na fase adulta, como, por exemplo, no intenso manipular de recursos digitais que o indivíduo realiza quando de sua aquisição, independentemente da idade.

Os jogos simbólicos são marcados pela representação fictícia com vistas à satisfação pessoal, com vínculos totalmente subjetivos entre significante e significado. Fazem prevalecer, no caráter de assimilação deformante, uma "[...] verdade individual em oposição à verdade impessoal e coletiva" (ibid., p. 214). O símbolo está presente já nas fases iniciais do estágio pré-operatório (2-7 anos), nas brincadeiras de faz-de-conta, nas imitações e fabulaçôes infantis. Persiste no adulto que conta histórias e em atividades de jogadores de Role-Playing-Game (RPG), brincadeira que, em geral, principia no final da adolescência/início da juventude, mas pode se estender às fases ulteriores da vida.

A última estrutura, caracterizada pelo aparecimento da regra, supõe relações sociais ou interindividuais, baseia-se em uma organização coletiva e implica a obediência a determinadas regularidades, em geral impostas pelo grupo. Instala-se na fase operatória concreta (7-11 anos), mas seu desenvolvimento permanece ao longo da vida. A regra anuncia o equilíbrio entre a assimilação ao eu e a vida social, conciliando o caráter lúdico à necessidade de reciprocidade social. Jogos como xadrez, esportes e cartas em geral são competitivos e, portanto, correlatos à socialização do indivíduo: não se estabelecem na solidão. Em geral, suas regras não são espontâneas, sendo impostas pelas geraçôes precedentes ou por acordos momentâneos, mas sempre com base no vivido. Na atualidade, os jogos de regras podem se estabelecer entre o indivíduo e a máquina: games ou jogos de computadores, que oporão os dois competidores, o biológico e o maquínico. Outras variedades de jogos desenvolvidos para/em computadores opõem jogadores virtuais em mundos imaginários.

A abordagem piagetiana destaca o papel do jogo no desenvolvimento sócio-cognitivo, sobretudo em sua dimensão de fonte da imaginação criadora que, segundo o autor, seguirá se 
constituindo como propulsora de todo pensamento ulterior e mesmo da razão. Visualiza-se, em sua teoria, um enfoque que não se restringe ao caráter lúdico, embora dele se beneficie para a construção conceitual:

O simbolismo desabrocha primeiro essa assimilação num sentido egocêntrico; depois, com o progresso duplo de uma interiorização do símbolo na direção da construção representativa e de um alargamento do pensamento na direção conceptual, a assimilação simbólica se reintegra no pensamento sob a forma de imaginação criadora. (ibid., p. 199)

Ao assumir o jogo, conforme propõe Piaget, como integrante efetivo da inteligência, tornando-se construtivo e conduzindo à representação adaptada, destacamos a pertinência de sua utilização na busca e no diagnóstico do desenvolvimento da conceituação, sobretudo quando contextualizado em um ambiente de imersão digital, profícuo à mobilização de competências próprias da sociedade do conhecimento.

\section{O experimento}

A partir do arcabouço teórico explicitado, passamos à experimentação pertinente. Evidentemente, desejávamos a utilização de um game que efetivamente estivesse ao alcance do aluno, tanto no aspecto cognitivo quanto no de sua disponibilização física. Era, pois, imprescindivel que a escolha se fizesse no universo das possibilidades do material escolar disponível. A seguir, discorremos sobre a construção e implementação do experimento.

\section{A escolha do jogo}

Em janeiro de 2005, por ocasião do Fórum Econômico Mundial, realizado em Davos (Suíça), a ideia de um computador por aluno, concebida pela organização OLPC (One Laptop per 
Child), foi apresentada ao governo do Brasil ${ }^{8}$. O projeto prépiloto $^{9}$ de adoção da modalidade de aprendizagem 1:1 (Um Computador por Aluno - UCA) no País contextualiza o experimento deste artigo.

O laptop XO foi projetado especialmente para atender crianças de países em desenvolvimento, que vivem em alguns dos mais remotos ambientes do mundo. Como as crianças crescem e buscam novas ideias, os softwares e as ferramentas disponíveis devem ser capazes de permitir esse crescimento e proporcionar uma ponte para outras tecnologias.

No XO, para o experimento proposto, elege-se o Implode, jogo de lógica, basicamente estrutural, uma vez que prescinde de narrativa. O jogo, em que grupos de pelo menos três blocos da mesma cor colapsam quando clicados, apresenta como meta limpar a tela. Na figura 1, apresentamos a tela inicial do Implode. A própria OLPC classifica o Implode como um jogo de lógica baseado no cair de blocos, ou seja, um modelo de Tetris ${ }^{10}$.

8 Em junho de 2005, Nicholas Negroponte, a cientista Mary Lou Jepsen e Seymour Papert vieram pessoalmente ao Brasil para uma audiência com o presidente Luiz Inácio Lula da Silva (HOLLANDA, 2005). Em novembro de 2006, Domingos registrou a entrega do The Children's Machine (XO) por Negroponte ao presidente do Brasil, primeiro chefe de Estado no mundo disposto a implementá-lo. Assim, o "XO gerou grande debate", afirma Markoff (2006). Tudo isto catapultou para âmbito nacional as discussões sobre a informática na educação através do popularmente conhecido "Laptop de 100 dólares", "2Bl” ou "Laptop das crianças", efetivamente, "uma maquininha com uma grande missão".

9 A iniciativa do Governo Federal envolveu, na primeira fase, cinco escolas de diferentes regiões do país - São Paulo (SP), Piraí (RJ), Palmas (TO), Brasília (DF) e Porto Alegre (RS) -, que testaram três modelos de equipamentos: Classmate, fabricado pela Intel; Mobilis, criado pela Encore e XO, desenvolvido pela organização não governamental OLPC. Na atual fase do projeto, denominada PROUCA, cerca de 300 escolas públicas brasileiras estão contempladas e utilizam o laptop do consórcio CCE/DIGIBRAS/METASYS. Disponível em: <http://www.uca.gov.br/institucio$\mathrm{nal} /$ projeto.jsp>. Acesso em: 28 out. 2010.

10 Tetris (em russo: Тетрис) é um jogo muito popular desenvolvido entre 1984 e 1986 por Alexey Pajitnov (Pazhitnov), Dmitry Pavlovsky - engenheiros informatas do Centro de Computação da Academia Russa de Ciências - e Vadim Gerasimov, estudante do ensino médio, então com 16 anos. O objetivo do jogo é encaixar tetraminós, que são peças de diversos formatos que descem do topo de uma tela. Quando uma linha é completada, desaparece. O sucesso foi muito grande para um jogo tão singelo, e sua popularidade foi atribuída à sua simplicidade e ao enorme 
O jogo inicia com uma grade parcialmente preenchida de blocos. $\mathrm{O}$ jogador faz movimentos para remover blocos adjacentes da mesma cor em grupos de pelo menos três. Quando os blocos são removidos, os que estão acima caem para preencher o espaço vazio. A cada coluna apagada, os blocos se encaixam no espaço resultante. O objetivo do jogo é remover todos os blocos. Uma vez que os padrões de blocos superiores mudam quando blocos inferiores são removidos, o jogador deve decidir a ordem em que irá remover os blocos de modo que não restem blocos isolados ao fim do jogo, nos diversos níveis de dificuldade.

Figural: Tela inicial do Implode, na máquina XO

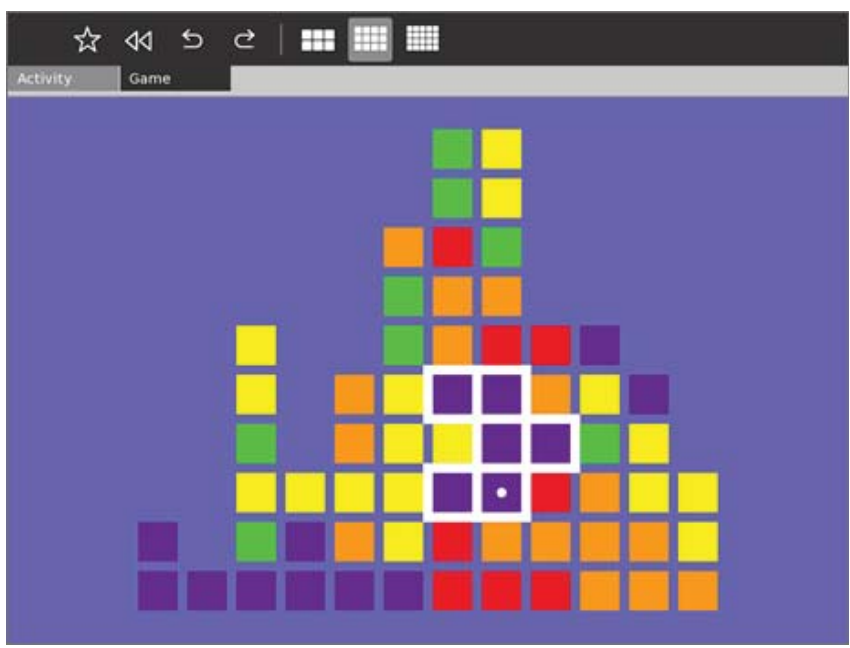

Fonte: One Laptop per Child (OLPC)

\section{Metodologia}

Buscando verificar o entendimento dos alunos sobre o jogo apresentado, utilizamos uma metodologia de investigação que

contraste que possui em relação a uma série de jogos que envolvem violência e outros comportamentos semelhantes. Foi adaptado para várias plataformas diferentes (GERASIMOV, 2009). 
lhes permitisse descrever sua experiência com o jogo: a entrevista clínica piagetiana.

O método hipotético-dedutivo proposto por Piaget (DELVAL, 2002) apresenta como propósito a livre expressão do sujeito de modo a comunicar aspectos básicos de seu pensamento. Contudo, tal liberdade não deve ser confundida com a ausência de objetivos: na observação do processo cognitivo e durante a coleta de dados, o pesquisador formula hipóteses relacionadas a metas claras de investigação, validadas ou refutadas a cada resposta do entrevistado.

Ainda que questões possam ser elaboradas de antemão, não há um roteiro fixo pré-determinado: diferentes indagações podem se fazer necessárias no decurso da pesquisa a fim de esclarecer a organização do pensamento da criança. Um determinado número de questôes básicas semelhantes em diferentes aplicações é útil à medida que desejamos estabelecer comparações entre sujeitos, mas as questôes a que podemos, segundo Delval (2002), chamar complementares é que evidenciam a riqueza do método e diferenciam-no de entrevistas padronizadas. Isso significa uma elaboração prévia de questões iniciais e uma panorâmica de pontos a serem atingidos, mas, a priori, nunca se conhecem todas as interrogações a serem realizadas ou o direcionamento real a ser obtido durante o experimento.

Outro diferencial da metodologia consiste na apresentação de perguntas de controle ou contra-sugestões, em que se fornece uma explicação distinta daquela concedida pelo sujeito a fim de verificar a estabilidade de sua convicção. Neste caso, em geral, utiliza-se a figura de um sujeito fictício, de idade e contexto próximos ao do entrevistado, a fim de evitar interferências da imagem de autoridade do pesquisador, que poderiam sugestioná-lo. Convém que tal estratégia seja deixada para o fim da entrevista, momento em que a contra-sugestão já não alterará outras respostas do sujeito.

A linguagem usada pelos dois pólos - observado e observador - deve ser a mesma ou, no mínimo, intercomunicável. É 
importante manter o cuidado de verificar o entendimento das crianças sobre as expressões utilizadas pelo entrevistador e, concomitantemente, especificar o sentido do vocabulário aplicado pela criança. Também o ambiente no qual se desenrola o experimento deve ser o mais próximo do cotidiano da criança, apontando que a escola faz parte desse cotidiano.

Cabe destacar, finalmente, que a entrevista clínica piagetiana não se destina à mensuração, mas à identificação, por meio da observação da forma como o pensamento se organiza, do nível de conceituação do sujeito em relação à temática abordada. Feitas as considerações sobre o método, procedemos à descrição do experimento.

\section{Descrição do experimento}

O experimento foi realizado numa escola estadual de ensino fundamental localizada em Porto Alegre e um dos polos da experiência pré-piloto de testagem da modalidade 1: 1 no Brasil, com três meninas do primeiro ano do Ensino Fundamental de nove anos. Cada criança, na época, tinha sete anos completos. Elas foram enviadas pela professora de acordo com seu próprio critério de escolha. Inicialmente, conversamos com elas numa sala de recreação e, posteriormente, nos dirigimos ao laboratório de informática. Naquela ocasião, foi-lhes informado que estávamos fazendo um trabalho com computadores e que gostaríamos da sua ajuda. Foi-lhes dada a opção de colaborar na pesquisa ou não. Certificamo-nos, também, de que elas ainda não usavam o XO na escola (as máquinas não haviam sido distribuídas ao primeiro ano em 2009), embora duas delas tenham nos informado que possuíam acesso a computadores: a criança EMI porque a família tinha computador; a criança NAT porque o irmão, estudante na mesma escola em outra série, levava o laptop para casa. A criança KAT manteve-se em silêncio. A fim de possibilitar uma discussão por todos do grupo em tempos e circunstâncias diversas e uma observação mais acurada, as entrevistas foram gravadas. 
No laboratório de informática, apresentamos os laptops às crianças. Fornecemos uma explicação básica sobre o seu uso ligar, acesso ao software, uso das teclas com as setas para frente, para trás, direita e esquerda, espaço, etc. Chamou-nos a atenção o comportamento da criança KAT, que testava o que falávamos e esclarecia as dúvidas com as colegas, principalmente com NAT. O comportamento de KAT nos indicava que o uso de microcomputador era desconhecido por ela. Previamente, elaboramos algumas questões que seriam levantadas - (i) pode me explicar $o$ que você fez?; (ii) você ganhou ou perdeu?; (iii) como você sabe? - e elegemos a pessoa que faria a entrevista. Elucidamos ainda que, inicialmente, uma criança de cada vez participou do experimento e, num segundo momento, as três o fizeram conjuntamente. Segue-se, a partir de agora, a descrição e análise das entrevistas.

A criança EMI procedeu a inúmeras jogadas, mas não explicou como jogava, nem, num primeiro momento, se ganhava ou perdia o jogo. Mesmo após comentários do entrevistador sobre a presença ou a ausência de uma carinha ao fim das jogadas, a criança parecia não relacionar o fato a ganhar ou perder o jogo. Contudo, apresentava grande destreza e agilidade no seu manuseio, fornecendo indícios da compreensão de seu funcionamento e do alcance do entendimento da regra subjacente. A construção de estratégias para a remoção de todas as peças, no entanto, não aconteceu. Ao fim da entrevista, a aluna passou a afirmar se ganhava ou não o jogo, mas persistiu não explicando como sabia o resultado ou qual o percurso adotado. Assinalamos que EMI nos pareceu muito tímida.

A criança KAT, inicialmente, perguntou o que teria que fazer para jogar. Realizou a exploração após o convite do entrevistador para que mexesse como quisesse. A dica fornecida, a exemplo do que acontecera com EMI, foi a de que clicasse na Estrelinha para iniciar o jogo. Alguns excertos da entrevista, apresentados nos quadros a seguir, são ilustrativos do papel da intervenção orientada no método clínico piagetiano no intuito da verificação do nível de conceituação da criança acerca da presença da regra e no auxílio a tomadas de consciência por parte da aluna. 


\section{Quadro 1}

KAT: Que que eu tenho que fazer?

P: Não sei. Será que você descobre? Pode mexer.

\section{Quadro 2}

P: E como é que você tá jogando, você consegue me explicar?

KAT: Aluna hesita e realiza novas tentativas.

P: Você tem irmão, KAT?

KAT: Sim.

P: Se você tivesse que dizer ao seu irmão o que você fez hoje na escola, o que você falaria para ele?

KAT: Que eu joguei.

P: E como você explicaria para ele como você jogou?

KAT: Clicando nos quadradinhos...

P: Qualquer quadradinho?

KAT: Não. Só o que junta.

\section{Quadro 3}

P: Tem quadradinho junto?

KAT: Tem.

P: E por que não dá?

KAT: Porque tem um amarelinho e dois vermelhos.

$\mathrm{P}$ : E precisa de quantos?

KAT: Um monte.

P: Um monte? Tenta jogar de novo. (durante jogada):

Você consegue me dizer um monte quantos?

KAT: Cem. 


\section{Quadro 4}

P: Me explica como você tem que fazer para ganhar esse jogo. Perguntei como você joga, você explicou. Agora eu quero saber quando você quer ganhar como você tem que fazer.

KAT: Eu tenho que clicar nos quadradinhos os que tão juntos, e daí se tu clicar um do lado do outro daí tu ganha.

O quadro 1 remete a uma das premissas da entrevista clínica piagetiana. Tendo em vista o objetivo de conhecer o modo como o pensamento da criança opera, não há razão para entregar a regra. Sobretudo no caso da presente pesquisa, é sobre a tomada de consciência acerca da presença da regra que a entrevista se desenrolará, e é nesta compreensão que se sustentarão os esforços de intervenção e análise. O mesmo princípio se aplica às diversas atividades realizadas com a criança no sentido de instigar e visualizar o funcionamento de seu pensamento.

No quadro 2, é exemplificada uma estratégia utilizada para incentivar a expressão da criança, trazendo a informação a um contexto próximo e buscando conferir sentido a sua manifestação. O quadro 3 ilustra o momento de provável tomada de consciência quanto à necessidade da presença de um determinado número de blocos de mesma cor unidos para que se pudesse proceder a sua remoção. Contudo, o número exato não é conhecido da criança e, possivelmente, o conhecimento de tal informação ainda não se constitui em uma necessidade para KAT, visto que se contenta com respostas que remetam a uma quantidade elevada, como $\mathrm{um}$ monte e cem. A compreensão da presença da regra é confirmada por meio da verbalização do quadro 4 , e as jogadas da criança orientam-se no sentido de alcançar o objetivo proposto, embora estratégias de antecipação e verificação não se mostrem presentes. 
Destaca-se o fato de que, ao princípio do jogo, a aluna não explicava os procedimentos realizados, nem se ganhava ou perdia, conduta semelhante à verificada em EMI.

A criança NAT já conhecia o XO, conforme anteriormente especificado. Entretanto, demonstrou dificuldades em trabalhar com o jogo apresentado. Em relação às colegas, utilizou mais tempo explorando sua interface. Novamente, a apresentação de extratos da entrevista permite examinar algumas nuances do processo de intervenção, bem como seus efeitos sobre a conduta da criança.

\section{Quadro 5}

NAT: Tem que montar? Tem que botar algum no cantinho?

P: Não sei, temos que descobrir.

(...)

NAT: Que que eu tô fazendo?

P: Que que você tá fazendo?

NAT: (Depois de alguns instantes, ao visualizar uma formação de peças semelhante a uma letra ' $L$ ” invertida horizontalmente, exclama): "L"!

P: Acabou? Não pode clicar mais, não?

NAT: (Ao clicar e concluir o jogo): Só fiz um sorriso... (...)

P: Você consegue me explicar como você tá jogando? NAT: Eu queria montar um caminhão, mas eu não tava conseguindo.

P: Ah, você queria montar um caminhão mas não tava conseguindo. Então você tá achando que é um jogo de montar. E se for de desmontar?

NAT: É, ele tenta desenhar mesmo assim, daí tu tira um, tu clica com o botão e tira outro, e vai formando teu desenho. 


\section{Quadro 6}

NAT: Deu (restando uma peça).

P: Você ganhou ou perdeu?

NAT: Ganhei.

P: Você acha que ganhou. Por que você ganhou?

NAT: Porque eu tirei todas as peças, só sobrou uma.

P: Ah, então quando você tira todas as peças e fica só uma você ganha, é isso?

NAT: É.

(Após nova tentativa, restam algumas peças na tela, sem a possibilidade de que sejam removidas)

P: Você ganhou ou perdeu?

NAT: Perdi.

P: Por quê?

NAT: Porque eu não consegui tirar todas as peças.

\section{Quadro 7}

P: E agora, como você tá jogando? Me explica.

NAT: Tô tirando as peças.

P: E quando que você consegue tirar as peças?

NAT: Hesita.

P: Essa ai você consegue tirar?

NAT: Não.

P: Por quê?

NAT: Porque tem a bolinha.

Em seguida, após novas tentativas.

P: Conseguiu tirar? Por que você conseguiu tirar?

NAT: Porque tinha uma bolinha? 


\section{Quadro 8}

P: Conseguiu? Por quê?

NAT: Aqui tem isso aqui ó (aponta o contorno que circunda peças suscetiveis de serem removidas). Quando tem só um desse aqui (aponta peça isolada), daí não pode clicar.

(...)

P: E agora, você ganhou ou perdeu?

NAT: Ganhei.

P: como você sabe?

NAT: Porque tem um sorriso, quando tá para baixo é por causa que eu não ganhei.

P: Quando tá para baixo você não ganhou, assim tá para cima você ganhou?

NAT: É.

P: E o que aconteceu no jogo para você ganhar?

NAT: Eu tirei todas as peças.

Observa-se, pelos fragmentos exibidos no quadro 5, a acepção simbólica de NAT diante do jogo, que busca suprir a expectativa pessoal de montar seus próprios desenhos, a despeito de o propósito do jogo constituir-se em eliminar blocos. Assim, a aluna mostra-se satisfeita com o reconhecimento de uma imagem próxima à representada pela letra 'L' (evitando, inclusive, efetuar o último clique que a levaria à vitória), expressa seu desejo de montar um caminhão, julga ter construído o sorriso que automaticamente aparece a cada vitória conquistada e resiste à sugestão do entrevistador quanto à possibilidade de o jogo se tratar de um jogo de desmontar, afirmando que, mesmo neste caso, desenhos seriam formados.

O registro do quadro 6 denota a mudança conceitual da aluna perante o jogo, procedendo ao reconhecimento da regra, 
ainda que, no princípio da tomada de consciência, haja resquícios de assimilação deformante: NAT julga que, havendo um bloco remanescente, a vitória seria alcançada. Nota-se que, a partir da visualização de um maior número de blocos restantes (cuja remoção era impossibilitada pela ausência de três peças de mesma cor adjacentes), a aluna demonstra um aprimoramento de sua compreensão, à medida que atribui o insucesso ao fato de não ter conseguido eliminar todas as peças. A exposição de NAT no quadro 8 confirma seu entendimento da regra, bem como a inferência da existência de um bonequinho com boca virada para baixo, remetendo ao aspecto de tristeza. Tal contraponto à vitória é trazido pela aluna a título de explanação sobre seu alcance ou não, embora o referido desenho não aparecesse efetivamente na tela. Algumas indiferenciações são igualmente percebidas no decurso da entrevista, como no quadro 7, em que a presença da bolinha (localizada no conjunto de blocos suscetíveis ao clique para a remoção) é atribuída tanto a casos de possibilidade quanto de impossibilidade de eliminação.

Outro fator relevante a ser considerado na entrevista com NAT é a importância da intervenção ao permitir a condução de um exame processual, e não focado em um resultado isolado: apesar da vitória na primeira tentativa, verificamos no decorrer da entrevista que se tratava de um fenômeno casual, uma vez que a compreensão sobre o funcionamento e a regra do jogo só foi construída após diversas intervenções do entrevistador, tentativas e tomadas de consciência da aluna.

Finalmente, as três crianças foram reunidas para jogarem juntas. Ajustamos o jogo para a dificuldade máxima. Tentamos impor as seguintes regras: jogaria uma de cada vez, em qualquer ordem; antes de jogar, explicariam o que iriam fazer. Rapidamente se organizaram, estabelecendo um rodízio entre elas, e modificaram as regras estabelecidas pelos entrevistadores, chegando, no entanto, a um acordo que satisfazia a todas: cada uma realizava um determinado número de jogadas e cedia a vez para a próxima colega, sem explicar ou discutir as jogadas, ou seja, sem socializar as descobertas empreendidas. 


\section{Discussão do experimento}

Como anteriormente colocado, as crianças que fizeram parte de nosso experimento encontram-se na idade em que se costuma verificar o princípio do reconhecimento e do uso do jogo de regras. Entretanto, não há uma relação pré-determinada ou imediata entre idade e estrutura cognitiva manifesta quando se tem como arcabouço a teoria piagetiana do desenvolvimento. Ao contrário, faz-se necessária a intervenção orientada por objetivos claros e focada na livre expressão da criança para que as competências e o nível de desenvolvimento efetivamente apresentados sejam exibidos e possam ser mobilizados.

Apontamos que as crianças investigadas encontram-se, provavelmente, em situação limítrofe entre os jogos simbólicos e os jogos de regras. Ao menos uma das crianças - NAT - deixou clara sua interpretação simbólica do jogo, expressando seu desejo de construir desenhos ao perceber quadradinhos pintados com cores diferentes. Entretanto, essa mesma criança propôs hipóteses para a retirada das peças e, ao testá-las, descobriu a regra estabelecida. Também KAT testou cor, posição e número para a remoção dos blocos e consequente vitória no jogo, empreendendo diversas tentativas bem-sucedidas em relação à regra. Nenhuma das alunas entrevistadas evidenciou a composição de estratégias para ganhar o jogo, embora todas tenham demonstrado reconhecer quando ganhavam ou perdiam. Reiteramos a importância da entrevista clínica na condução do processo de reconhecimento da regra e na manifestação das tomadas de consciência que conduziram as crianças ao aprimoramento de sua compreensão.

Um último aspecto a ser considerado é a dificuldade de obediência a regras exógenas ausentes do ambiente do jogo. A despeito da anuência em relação às regras estabelecidas pelos entrevistadores adultos para a realização coletiva de jogadas, as alunas, quando colocadas para jogar juntas, acabaram por elaborar novas regras, sobre as quais estivessem de comum acordo, 
respeitando apenas estas últimas e tornando-se independentes em relação aos proponentes do experimento.

Por mais excitadas e animadas que se encontrassem a propósito da situação do experimento, as crianças respeitaram tanto o material como as pessoas nele envolvidas. É preciso assinalar, ainda, o caráter de cooperação do grupo: a criança que conhecia a máquina dispôs-se a ensinar suas colegas a utilizá-la e cada uma mostrou às demais aquilo que conseguia fazer com o $\mathrm{XO}$ no espaço e no momento adequados.

\section{Conclusões}

Ao longo do desenvolvimento do experimento, buscamos entender as condutas observadas e suas relações com o uso de jogos como ferramenta pedagógica. Caracteristicamente, a ludicidade presente nas ações desenvolvidas pelas crianças e apontada por Huizinga (2008) pôde ser observada, assim como a atenção às regras, mas não àquelas impostas. A possibilidade de criação de novas regras também foi contemplada e negociada pelas crianças participantes. A questão a se destacar nesse quesito pode ser considerada como percepção dos diferentes lugares ocupados: quando a ação se desenrolava envolvendo a máquina e a criança, as regras foram descobertas e, no processo, nunca negociadas. A situação foi sobremaneira evidente quando do uso que a criança NAT tentou fazer do jogo, ao percebê-lo como possibilidade de montar uma forma conhecida ou ao reconhecer um desenho fortuito construído (a letra $L$ ). A negociação de novas regras, entretanto, se deu no momento em que puderam socializar a ferramenta, rompendo com aquelas exógenas - propostas pelos observadores -, mas respeitando as observadas a partir da experiência com a máquina. Nesse contexto, parecem compreender as diferentes posições assumidas pela máquina e por pessoas, embora não tenham concedido papéis especiais para os coletivos distintos: observadas e observadores. 
A possibilidade de reinício constante (MURRAY, 2003; PRENSKY, 2007; PAPERT, 1998), ao lado das negociações oportunizadas, ensejou descobertas, construçóes, testagens e reconstruções das possibilidades levantadas. Confirmando a proposta de Veen e Vrakking (2008), mesmo a criança que aparentemente tinha pouco contato com a ferramenta (XO) apropriou-se rapidamente da mesma, passando a zapear com segurança e intimidade. Lembramos que a invenção do verbo relaciona-se também com outras facilidades cotidianas, como o uso de controle remoto em aparelhos eletro-eletrônicos e o teclar em modelos diversos de telefones. Não sabemos precisar a utilização que tal criança faz dos instrumentos citados.

Observamos ainda, de maneira agradavelmente didática, as colocações de Macedo et al. (2000) sobre as formas de jogar das crianças. Destacamos que cada uma delas passou pela exploração do material disponibilizado, descobrindo as regras, mas não conseguindo ainda compor estratégias para o jogo em grupo. Assim, apesar de socializarem conhecimentos prévios sobre o meio - computador -, não puderam realizar o mesmo em relação à descoberta das regras para o uso específico do jogo apresentado. Nesse contexto, a cooperação se dá mais no nível da explicitação de regras para compartilhamento do instrumento.

Finalmente, buscando Piaget $(1976 ; 1983 ; 1990)$ como ponto de partida - que se constitui também naquele de chegada, embora em plano diferente -, foi possível verificar a mobilização de esquemas mentais pelas crianças, concentradas na pesquisa que realizavam, buscando as ações necessárias para o uso da ferramenta disponibilizada. Trabalharam diligentemente propondo e testando hipóteses. E mesmo a mais tímida delas frequentemente murmurava enquanto realizava o que, mentalmente, havia se proposto a fazer. Pudemos apreender a situação limítrofe em que se encontravam entre o jogo simbólico e o de regras. Consideramos importante assinalar tal fase como forma de manter nossa atenção focada no que realizam com sucesso e naquilo que ainda não fazem de forma bem-sucedida a fim de auxiliá-las rumo a um nível superior de desenvolvimento conceitual. 
É de suma importância a concepção de projetos educacionais que incluam o contato da criança com a tecnologia da informação. Mais do que assumirmos a existência de uma nova geração de alunos - os "nativos digitais" (PRENSKY, 2007) ou "homo zappiens" (VEEN; VRAKKING, 2009) -, devemos provê-los com usos que beneficiem e incentivem seu desenvolvimento, aliando ao caráter lúdico de iniciativas pautadas nas novas tecnologias a dimensão construtiva das propostas, no sentido de constituí-los como "letrados digitais".

A ideia de que esses alunos podem aprender de forma divertida é, sem dúvida, bem-vinda, embora não se constitua em novidade. No que se refere aos jogos informatizados, podemos nos valer do trabalho com múltiplas competências requeridas pela sociedade do conhecimento - reflexão crítica, processamento ativo de informações, convívio com a mudança, habilidade comunicacional, negociação e, conforme o foco do nosso trabalho, estabelecimento de relações interindividuais profícuas com respeito às regras sociais -, sobretudo quando munidos de métodos que incentivem a livre expressão de ideias e do operar do pensamento. A esse respeito, pretendemos ter aqui oferecido nossa contribuição.

Entretanto, há que se atentar a alguns aspectos: os jogos propostos de fato orientam-se no sentido do desenvolvimento do público-alvo? O enfoque realmente se realiza sobre as habilidades que os alunos constroem ou repousa sobre o imaginário tecnológico que os donos do saber detêm? E, fundamentalmente, que usos e que métodos propiciam um pleno aproveitamento das propriedades dos jogos para o desenvolvimento cognitivo da criança?

Se é função da escola favorecer a socialização do sujeito, tornando-o apto a viver em comunidades com seus valores, regras e imaginários (em constante transformação na cultura digital), nesse estudo, esperamos ter contribuído para assinalar a possibilidade de construção de perspectivas sobre novos usos pedagógicos do jogo digital. Tais perspectivas privilegiam a tomada 
de consciência dos sujeitos sobre o próprio fazer e a aceitação da existência de normas e regras que regulam as relações sociais, em cuja elaboração poderão operar participativamente. Esse estudo abre a oportunidade da realização de novos experimentos com diferentes faixas etárias na direção do desenvolvimento de competências como as anteriormente apontadas, dentre as quais destacamos a imaginação criadora, a cooperação, a programação de jogos digitais pelo aluno e a construção de novos saberes.

\section{Referências}

BENJAMIN, Walter. Sobre Arte, Técnica, Linguagem e Política. Lisboa: Relógio D’Água, 1992.

DELVAL, Juan. Introdução à prática do Método Clínico: descobrindo o pensamento das crianças. Porto Alegre: Artmed, 2002.

DOMINGOS, Roney. Lula recebe primeiro laptop de programa para equipar escolas. G1. São Paulo, nov. 2006. Disponível em: <http:// g1.globo.com/Noticias/Politica/0,,AA1362660-5601-413,00.html>. Acesso em: 21 nov. 2009.

FIRST XO-2 Mockup Spotted at WEF in Davos. Disponível em: <http:// www.olpcnews.com/laptops/xo2/first_xo-2_mockup_spotted_at_wef. html>. Acesso em: 21 nov. 2009.

GERASIMOV, Vadim. Tetris Story. Disponível em: <http://vadim. oversigma.com/Tetris.htm>. Acesso em: 23 jun. 2011.

HOLLANDA, Eduardo. O livro do futuro. ISTOÉ Online. São Paulo, jul. 2005. Disponível em: <http://www.istoe.com.br/reportagens/7205_O+ LIVRO+DO+FUTURO?pathImagens $=\&$ path $=\&$ actualArea $=$ internalPa ge>. Acesso em: 23 jun. 2011

HUIZINGA, Johan. HOMO LUDENS: o jogo como elemento da cultura. São Paulo: Perspectiva, 2008.

IMPLODE - OLPC. Disponível em: <http://wiki.laptop.org/go/Implode>. Acesso em: 20 nov. 2009.

LÉVY, Pierre. O que é o virtual? São Paulo: Editora 34, 1996. 
MACEDO, Lino de; PETTY, Ana Lucia Sicoli; PASSOS, Norimar Christe. Aprender com jogos e situações-problema. Porto Alegre: Artmed, 2000.

MARKOFF, John. For \$150, Third-World Laptop Stirs Big Debate. The New York Times. New York, nov. 2006. Disponível em: $\quad<$ http://www.nytimes.com/2006/11/30/technology/30laptop. html ? pagewanted $=1 \& \mathrm{sq}=$ Nicholas $\% 20$ Negroponte $\% 20 \% 20$ lula\&st=cse\&scp=2>. Acesso em: 21 nov. 2009.

MAYR, Ernst. O Desenvolvimento do Pensamento Biológico: diversidade, evolução e herança. Brasília: UNB, 1998.

MURRAY, Janet. Hamlet no Holodeck: o futuro da narrativa no ciberespaço. São Paulo: UNESP, 2003.

ONE LAPTOP PER CHILD (OLPC): A low-cost, connected laptop for the world's children's education. Disponível em: <http://laptop.org/en/ laptop/software/activity8.shtml>. Acesso em: 20 nov. 2009.

PAPERT, Seymour. Does Easy Do It? Children, Games, and Learning. Game Developer, 1998. Disponível em: <http://www.papert.org/articles/ Doeseasydoit.html>. Acesso em: 15 out. 2009.

PIAGET, Jean; INHELDER, Barbel. Gênese das Estruturas Lógicas Elementares. Rio de Janeiro: Zahar Editores, 1976.

PIAGET, Jean. A Epistemologia Genética. São Paulo: Abril, 1983.

PIAGET, Jean. A Formação do Símbolo na Criança. Imitação, jogo e sonho, imagem e representação. Tradução de Álvaro Cabral. Rio de Janeiro: LTC, 1990.

PRENSKY, Marc. Digital game-based learning. Saint Paul, MN: Paragon House Publishers, 2007. Capítulo 1. Disponível em: <http://www. marcprensky.com/writing/Prensky\%20-\%20Ch1-Digital\%20GameBased\%20Learning.pdf > . Acesso em: 15 out. 2009.

PRENSKY, Marc. Are you lecturing about nouns or facilitating learning with verbs? Disponível em: <http://www.docstoc.com/docs/75470644/ Prensky-Article---Nouns-Verbs>. Acesso em: 23 jun. 2011.

PRENSKY, Marc. Verbs vs nouns. 2009. Disponível em: <http://www. marcprensky.com/blog/archives/000066.html>. Acesso em 13 maio 2010. 
VAN ECK, Richard. Digital game-based learning: it's not just the digital natives who are restless. EDUCAUSE Review, v. 41, n. 2. mar./abr. 2006. Disponível em: <http://www.educause.edu/ EDUCAUSE+Review/EDUCAUSEReviewMagazineVolume41/ DigitalGameBasedLearningItsNot/158041>. Acesso em: 17 nov. 2009.

VEEN, Wim. Learning strategies of homo zappiens: towards new learning arrangements. Disponível em: <http://www.learner.de/files/ newscenter/566_144242146_0001/Learning\%20Strategies\%20of\%20 Homo\%20Zappiens.pdf>. Acesso em: out. 2009.

VEEN, Wim; VRAKKING, Ben. Homo Zappiens: educando na era digital. Porto Alegre: Artmed, 2008. 